\title{
Acute type B aortic dissection complicated by visceral ischemia
}

\author{
Frederik H. W. Jonker, MD, PhD, ${ }^{\mathrm{a}, \mathrm{b}}$ Himanshu J. Patel, MD, ${ }^{\mathrm{c}}$ Gilbert R. Upchurch, MD, ${ }^{\mathrm{d}}$ \\ David M. Williams, MD, ${ }^{\mathrm{e}}$ Daniel G. Montgomery, BS, ${ }^{\mathrm{f}}$ Thomas G. Gleason, MD, MS, ${ }^{\mathrm{g}}$ \\ Alan C. Braverman, MD, ${ }^{\mathrm{h}}$ Udo Sechtem, MD, ${ }^{\mathrm{i}}$ Rossella Fattori, MD ${ }^{\mathrm{j}}$ Marco Di Eusanio, MD, PhD, ${ }^{\mathrm{k}}$ \\ Arturo Evangelista, MD, ${ }^{l}$ Christoph A. Nienaber, MD ${ }^{\mathrm{m}}$ Eric M. Isselbacher, MD, ${ }^{\mathrm{n}}$ Kim A. Eagle, MD, ${ }^{\mathrm{f}}$ and \\ Santi Trimarchi, MD, $\mathrm{PhD}^{\mathrm{a}}$
}

Objective: Acute type B aortic dissection (ABAD) can lead to visceral malperfusion, a potentially life-threatening complication. The purpose of this study was to investigate the presentation, management, and outcomes of ABAD patients with visceral ischemia who are enrolled in the International Registry of Acute Aortic Dissection.

\begin{abstract}
Methods: Patients with ABAD enrolled in the registry between 1996 and 2013 were identified and stratified based on presence of visceral ischemia at admission. Demographics, medical history, imaging results, management, and outcomes were compared for patients with versus without visceral ischemia.
\end{abstract}

\begin{abstract}
Results: A total of 1456 ABAD patients were identified, of which 104 (7.1\%) presented with visceral ischemia. Preoperative limb ischemia $(28 \%$ vs $7 \%, P<.001)$ and acute renal failure $(41 \%$ vs $14 \%, P<.001)$ were more common among patients with visceral ischemia. Endovascular treatment and surgery were offered to $49 \%$ and $30 \%$ of the visceral ischemia cohort, respectively; remaining patients were managed conservatively. The inhospital mortality was $30.8 \%$ for patients with visceral ischemia and $9.1 \%$ for those without visceral ischemia (odds ratio [OR] 4.44; 95\% confidence interval [CI], 2.8-7.0, $P<.0001$ ). Mortality rates were similar after surgical and endovascular management of visceral ischemia ( $25.8 \%$ and $25.5 \%$, respectively, $P=$ not significant). Among the visceral ischemia group, medical management was a predictor of mortality in multivariate analysis (OR, 5.91; 95\% CI, 1.2-31.0; $P=.036$ ).
\end{abstract}

Conclusions: Patients with ABAD complicated by visceral ischemia have a high risk of mortality. We observed similar outcomes for patients treated by endovascular management versus surgery, whereas medical management was an independent predictor of mortality. Early diagnosis and intervention for visceral ischemia seems to be crucial. (J Thorac Cardiovasc Surg 2015;149:1081-6)

\footnotetext{
From the Thoracic Aortic Research Center, ${ }^{a}$ Policlinico San Donato, Italy; Department of Surgery, ${ }^{\text {b }}$ Erasmus Medical Center Rotterdam, Rotterdam, The Netherlands; Cardiac Surgery Department, ${ }^{\mathrm{c}}$ University of Michigan, Ann Arbor, Mich; Division of Vascular and Endovascular Surgery, ${ }^{\mathrm{d}}$ University of Virginia Health System, Charlottesville, Va; Radiology Department, ${ }^{\mathrm{e}}$ University of Michigan, Ann Arbor, Mich; Cardiovascular Center, ${ }^{\mathrm{f}}$ University of Michigan, Ann Arbor, Mich; Division of Cardiothoracic Surgery, ${ }^{\mathrm{g}}$ University of Pittsburgh, Pittsburgh, Pa; Cardiovascular Division, ${ }^{\text {h }}$ Washington University School of Medicine, St. Louis, Mo; Division of Cardiology, ${ }^{\mathrm{i}}$ Robert-Bosch Krankenhaus, Stuttgart, Germany; Division of Interventional Cardiology, ${ }^{j}$ San Salvatore Hospital, Pesaro, Italy; Cardiac Surgery Department, ${ }^{\mathrm{k}}$ University Hospital S. Orsola, Bologna, Italy; Servei de Cardiologia, ${ }^{1}$ Hospital General Universitari Vall d'Hebron, Barcelona, Spain; Department of Internal Medicine, ${ }^{\mathrm{m}}$ University of Rostock, Rostock, Germany; and Thoracic Aortic Center, ${ }^{\mathrm{n}}$ Massachusetts General Hospital, Boston, Mass.

This work was supported by grants to the International Registry of Acute Aortic Dissection from Gore Medical Inc. (Flagstaff, Ariz); Ann \& Bob Aikens; the University of Michigan Health System (Ann Arbor, Mich); the Varbedian Fund for Aortic Research (Ann Arbor, Mich), the Mardigian Foundation (Bloomfield Hills, Mich), and Medtronic, Inc. (Minneapolis, Minn)

Disclosures: Authors have nothing to disclose with regard to commercial support.

Received for publication Aug 19, 2014; revisions received Oct 22, 2014; accepted for publication Nov 4, 2014; available ahead of print Dec 10, 2014.

Address for reprints: Frederik H. W. Jonker, MD, PhD, Thoracic Aortic Research Center, Policlinico San Donato IRCCS, University of Milan, Piazza Malan 2, 20097 San Donato Milanese, Italy; or Section of Vascular Surgery, Erasmus Medical Center Rotterdam, Laan op Zuid 258, 3011AA Rotterdam, The Netherlands (E-mail: jonkerfrederik@hotmail.com).

$0022-5223 / \$ 36.00$

Copyright (C) 2015 by The American Association for Thoracic Surgery

http://dx.doi.org/10.1016/j.jtcvs.2014.11.012
}

See related commentary on pages 1087-8.

丹 Supplemental material is available online.

Acute type B aortic dissection (ABAD) is a cardiovascular emergency of the descending thoracic aorta, which may lead to malperfusion syndromes of abdominal organs, the spinal cord, and the lower extremities. ${ }^{1-4}$ One of the most lethal complications of ABAD is the development of acute visceral ischemia, when the blood flow to the celiac and/or mesenteric arteries is diminished. Mortality rates of acute visceral ischemia have been reported to be as high as $25 \%$ to $62 \%,,^{5-13}$ and early intervention is generally indicated to restore intestinal blood flow. Various therapeutic options have become available for treating this aortic catastrophe, including various medical, endovascular, and surgical procedures. Because of its low incidence, little is known regarding the exact outcome of visceral ischemia caused by ABAD, or its optimal management. The International Registry of Acute Aortic 


$$
\begin{aligned}
\text { Abbreviations and Acronyms } \\
\text { ABAD }=\text { acute type B aortic dissection } \\
\text { CI }=\text { confidence interval } \\
\text { CTA = computed tomography angiography } \\
\text { IRAD = International Registry of Acute Aortic } \\
\\
\text { Dissection } \\
\text { NS }=\text { not significant } \\
\text { OR }=\text { odds ratio }
\end{aligned}
$$

Dissection (IRAD) has been enrolling patients with acute aortic dissection since 1996 and therefore may be useful to investigate acute malperfusion syndromes resulting from ABAD. The purpose of this study was to investigate the presentation, management, and outcomes of ABAD patients with visceral ischemia who are enrolled in the IRAD.

\section{METHODS \\ Patient Selection}

The International Registry of Acute Aortic Dissection is an ongoing multicenter registry that includes patients with acute aortic dissection at 30 large referral centers; the rationale and methods for the registry have been described elsewhere. ${ }^{14}$ For the present study, we included all patients with ABAD who were enrolled in the IRAD between January 1996 and December 2013. Patients were stratified based on the presence of visceral ischemia at admission. Visceral ischemia was defined as any radiologic evidence of decreased perfusion through the celiac trunk, the superior mesenteric artery, and the inferior mesenteric artery, with decreased viability or necrosis of the gut, with or without lactic acidosis, pain, or abdominal distention. Demographics, medical history, imaging results, management, and outcomes were subsequently compared between patients with versus without visceral ischemia. Institutional review committees at all participating IRAD institutions approved the study, and all subjects gave informed consent.

\section{Data Collection and Analysis}

Data were collected using a standardized data form of 290 clinical variables, including patient demographics, history, clinical presentation, physical findings, imaging studies, management, and in-hospital mortality. Completed data forms were forwarded to the coordinating center at the University of Michigan. Data forms were reviewed for internal validity and completeness of data, and entered into a database.

Summary statistics were presented as frequencies and percentages, mean \pm standard deviation, or as a median and interquartile range. Missing data were not defaulted to negative, and denominators reflect only actual reported cases. Nominal variables were compared between the two groups using the $\chi^{2}$ test or the 2-sided Fisher exact test; continuous variables were compared using the Student $t$ test or the Mann-Whitney $U$ test. The Cochran-Armitage test was used to investigate linear trends in management among patients with visceral ischemia in 3 time periods. Multivariate logistic regression analysis was performed to investigate independent predictors of in-hospital mortality among patients with visceral ischemia. Variables that were significant in univariate analysis $(P<.05)$ were integrated in a multivariable regression model to calculate independent effects on mortality. Kaplan-Meier survival estimates were used to investigate long-term survival for patients with and without visceral ischemia. SPSS 17.0 (SPSS Inc, Chicago, Ill) was utilized for the analyses, and a $P$ value $<.05$ was considered significant.

\section{RESULTS \\ Baseline Characteristics}

Overall, $1456 \mathrm{ABAD}$ patients were identified, of whom $104(7.1 \%)$ presented with visceral ischemia. Patients with visceral ischemia were younger than patients without visceral ischemia (59.1 vs 64.0 years, $P=.001)$. Patients with visceral ischemia presented more frequently with abdominal pain $(63 \%$ vs $40 \%, P<.001)$ and leg pain $(25 \%$ vs $11 \%, P<.001)$, whereas patients without visceral ischemia presented more often with chest pain $(71 \%$ vs $61 \%, P=.020)$. Femoral pulse deficits were more frequent in patients with visceral ischemia $(32 \%$ vs $13 \%, P<.001)$, and these patients presented more often with preoperative limb ischemia $(28 \%$ vs $7 \%, P<.001)$ and acute renal failure $(41 \%$ vs $14 \%, P<.001)$. There was a trend toward an increased incidence of spinal cord ischemia among these patients as well $(5 \%$ vs $2 \%, P=.054$; Table 1$)$.

\section{Imaging Results}

Computed tomography angiography (CTA) imaging showed that intramural hematoma was less common in type $\mathrm{B}$ dissection associated with visceral ischemia $(16 \%$ vs $34 \%, P=.001)$. Complete false lumen thrombosis was seen in $6 \%$ of patients with visceral ischemia, compared with $18 \%$ of patients without it $(P=.005)$. Abdominal vessel involvement was documented in $80 \%$ of the visceral ischemia group, compared with $38 \%$ in the remaining patients $(P<.001$; Table 2$)$.

\section{Management of ABAD With Visceral Ischemia}

Overall, endovascular treatment was offered to $49 \%$ of patients with visceral ischemia, compared with $21 \%$ of patients without visceral ischemia $(P<.001)$. Endovascular treatment consisted of stenting of the descending thoracic aorta (thoracic endovascular aortic repair) or abdominal branch vessels, or endovascular aortic fenestration (Table 3). Surgery was performed in $30 \%$ of cases of visceral ischemia and in $12 \%$ of remaining patients $(P<.001)$. Surgical treatment typically consisted of replacement of the descending thoracic aorta or surgical aortic fenestration (Table 3). Data regarding bowel resection were not available in the IRAD. Among patients without visceral ischemia, $67 \%$ were treated with medical treatment alone; this strategy was offered to just $21 \%$ of patients with visceral ischemia $(P<.001$; Table 3$)$.

Over the years, the management of visceral ischemia significantly changed in the IRAD. Between 1996 and $2001,47 \%$ of visceral ischemia patients were treated surgically, which decreased to $20 \%$ between 2002 and 2007, and to $16 \%$ between 2008 and $2013(P=.004$ for linear trend over time). The utilization of endovascular management for visceral ischemia increased from 35\% between 1996 and 2001 , to $50 \%$ between 2001 and 2007 , and to $68 \%$ 
TABLE 1. Baseline characteristics

\begin{tabular}{|c|c|c|c|}
\hline Characteristic & $\begin{array}{c}\text { Visceral } \\
\text { ischemia, } \\
\text { n }(\%)\end{array}$ & $\begin{array}{c}\text { No visceral } \\
\text { ischemia, } \\
\text { n (\%) }\end{array}$ & $P$ value \\
\hline Total patients & $104(7.1)$ & $1352(92.9)$ & \\
\hline \multicolumn{4}{|l|}{ Demographics } \\
\hline $\begin{array}{l}\text { Mean age } \pm \text { standard } \\
\text { deviation }(\mathrm{y})\end{array}$ & $59.1 \pm 13.7$ & $64.0 \pm 14.1$ & .001 \\
\hline Female & $30(28.8)$ & 469 (34.7) & .135 \\
\hline \multicolumn{4}{|l|}{ History } \\
\hline Marfan syndrome & $6(5.9)$ & $50(3.9)$ & .217 \\
\hline Hypertension & $80(79.2)$ & $1063(81.0)$ & .374 \\
\hline Atherosclerosis & $27(26.7)$ & $410(32.0)$ & .161 \\
\hline Diabetes & $4(4.0)$ & $107(8.4)$ & .080 \\
\hline Known aortic aneurysm & $14(14.1)$ & $274(21.3)$ & .056 \\
\hline \multicolumn{4}{|l|}{ Presentation } \\
\hline Chest pain & $59(60.8)$ & $920(71.2)$ & .022 \\
\hline Back pain & $69(69.0)$ & $892(70.2)$ & .437 \\
\hline Abdominal pain & $61(62.9)$ & $497(40.1)$ & $<.001$ \\
\hline Leg pain & $23(25.3)$ & $129(10.6)$ & $<.001$ \\
\hline Hypertensive & $64(68.1)$ & $826(65.6)$ & .353 \\
\hline Hypotensive/shock & $8(8.5)$ & $61(4.8)$ & .099 \\
\hline Femoral pulse deficits & $28(32.2)$ & $134(13.4)$ & $<.001$ \\
\hline \multicolumn{4}{|l|}{ Complications (preoperative) } \\
\hline Limb ischemia & $28(28.3)$ & $87(7.1)$ & $<.001$ \\
\hline Acute renal failure & $41(41.0)$ & $166(13.5)$ & $<.001$ \\
\hline Spinal cord ischemia & $5(5.2)$ & $23(1.9)$ & .054 \\
\hline
\end{tabular}

Values are $\mathrm{n}(\%)$, unless otherwise noted.

between 2008 and $2013(P=.005$ for linear trend over time). The frequency of definitive medical management did not change significantly over the years $(P=.506$; Figure 1).

TABLE 2. Imaging results

\begin{tabular}{lccc}
\hline \multicolumn{1}{c}{ Findings } & $\begin{array}{c}\text { Visceral } \\
\text { ischemia, } \\
\mathbf{n}(\%)\end{array}$ & $\begin{array}{c}\text { No visceral } \\
\text { ischemia, } \\
\mathbf{n}(\%)\end{array}$ & $\boldsymbol{P}$ value \\
\hline Total patients & $104(7.1)$ & $1352(92.9)$ & \\
Chest radiographs & & & \\
$\quad$ Normal & $24(26.7)$ & $307(23.8)$ & .464 \\
$\quad$ Widened mediastinum & $36(44.4)$ & $429(42.0)$ & .377 \\
Pleural effusion & $12(15.0)$ & $171(17.3)$ & .369 \\
CTA & & & \\
Intramural hematoma & $12(16.2)$ & $359(34.1)$ & .001 \\
Periaortic hematoma & $8(10.1)$ & $128(12.8)$ & .312 \\
Mean descending diameter (cm) & $4.0(3.3-4.9)$ & $4.0(3.5-5.0)$ & .225 \\
Status false lumen & & & \\
$\quad$ Patent false lumen & $39(59.1)$ & $422(53.6)$ & .231 \\
$\quad$ Partial thrombosis & $23(34.8)$ & $222(28.2)$ & .156 \\
$\quad$ Complete thrombosis & $4(6.1)$ & $144(18.3)$ & .005 \\
Location entry tear & & & \\
$\quad$ Left subclavian artery & $43(46.2)$ & $586(49.9)$ & .285 \\
$\quad$ Descending thoracic aorta & $23(24.7)$ & $318(27.1)$ & .362 \\
$\quad$ Abdominal aorta & $4(4.3)$ & $34(2.9)$ & .302 \\
Abdominal vessel involvement & $35(79.5)$ & $204(38.4)$ & $<.001$ \\
\hline Var
\end{tabular}

Values are $\mathrm{n}(\%)$, unless otherwise noted. CTA, Computed tomography angiography.
TABLE 3. Management of patients with and without visceral ischemia

\begin{tabular}{lccc}
\hline Definitive management & $\begin{array}{c}\text { Visceral } \\
\text { ischemia, } \\
\mathbf{n}(\%)\end{array}$ & $\begin{array}{c}\text { No visceral } \\
\text { ischemia, } \\
\text { n (\%) }\end{array}$ & P value \\
\hline Total patients & $104(7.1)$ & $1352(92.9)$ & \\
Medical management & $22(21.2)$ & $901(66.6)$ & $<.001$ \\
B-blockers & 19 & 719 & \\
Calcium channel antagonist & 14 & 554 & \\
ACE inhibitor & 11 & 488 & \\
Surgery & $31(29.8)$ & $161(11.9)$ & $<.001$ \\
$\quad$ Replacement of descending & 20 & 90 & \\
$\quad$ aorta & & & \\
Abdominal aortic repair & 2 & 9 & \\
Surgical aortic fenestration & 6 & 4 & \\
Other/unknown & 3 & 58 & \\
Endovascular management & $51(49.0)$ & $290(21.4)$ & $<.001$ \\
Endovascular aortic & 16 & 41 & \\
$\quad$ fenestration & & & \\
Thoracic stent graft & 32 & 224 & \\
Celiac/SMA/renal artery/ & 17 & 53 & \\
$\quad$ iliac stent & & & \\
\hline$A C E$, Angiotensin-converting enzyme; $S M A$, superior mesenteric artery. &
\end{tabular}

\section{Outcome of ABAD With Visceral Ischemia}

The in-hospital mortality rate was $30.8 \%(\mathrm{n}=32)$ for patients with visceral ischemia, compared with $9.1 \%$ $(\mathrm{n}=123)$ for those without visceral ischemia (odds ratio [OR], 4.44; 95\% confidence interval [CI], 2.81-7.01; $P<.0001)$. Definitive medical management of visceral ischemia was associated with a significantly increased mortality rate compared with invasive management of visceral ischemia $(50 \%$ vs $25.6 \%, P=.027)$. Mortality rates were similar after surgical and endovascular management of visceral ischemia $(25.8 \%$ and $25.5 \%, P=$ not significant

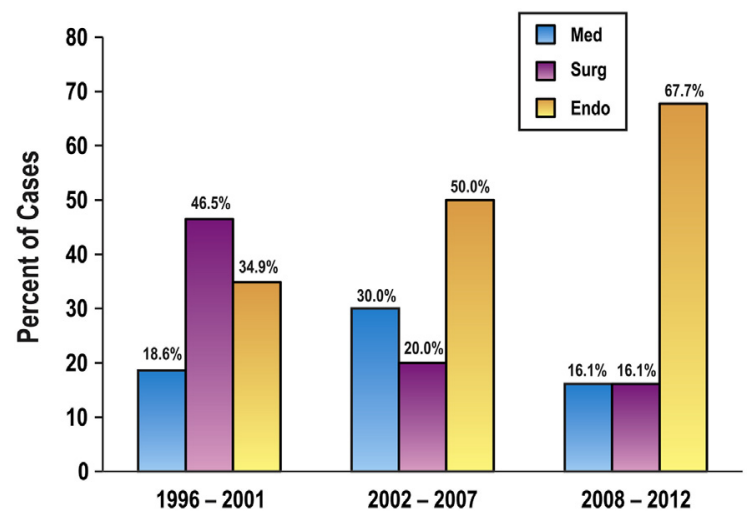

FIGURE 1. Management of visceral ischemia over the years in the International Registry of Acute Aortic Dissection. The utilization of surgery for the management of visceral ischemia significantly decreased during the 3 time periods $(P=.004$ for linear trend over time), whereas the utilization of endovascular management significantly increased $(P=.005$ for linear trend over time). Med, Medical management; Surg, surgery; Endo, endovascular management. 
TABLE 4. In-hospital mortality of patients with and without visceral ischemia

\begin{tabular}{|c|c|c|c|}
\hline Mortality & $\begin{array}{c}\text { Visceral ischemia, } \\
\text { n }(\%)\end{array}$ & $\begin{array}{c}\text { No visceral ischemia, } \\
\mathbf{n}(\%)\end{array}$ & $P$ value \\
\hline Total patients & $104(7.1)$ & 1352 (92.9) & \\
\hline Overall & $32(30.8)$ & $123(9.1)$ & $<.001$ \\
\hline Medical & $11(50.0)$ & $69(7.7)$ & $<.001$ \\
\hline Surgical & $8(25.8)$ & $25(15.5)$ & .131 \\
\hline Endovascular & $13(25.5)$ & $29(10.0)$ & .004 \\
\hline
\end{tabular}

[NS]). As compared with patients without visceral ischemia, mortality rates were higher after medical management $(50 \%$ vs $7.7 \%, P<.001)$, endovascular management $(25.5 \%$ vs $10.0 \%, P=.004)$, and surgery for visceral ischemia $(25.8 \%$ vs $15.5 \%, P=.131$; Table 4$)$. Among the visceral ischemia group, medical management was the only independent predictor of in-hospital mortality in multivariate analysis (OR, 5.91; 95\% CI, 1.2-31.0; $P=.036)$. A trend toward increased mortality was seen for patients with acute renal failure (OR, 3.71; $P=.064)$ and a descending aortic diameter $>5.5 \mathrm{~cm}$ (OR, 5.91; $P=.087$; Table E1).

For patients discharged alive, survival during 5 years of follow-up was not significantly different between patients that presented with versus without visceral ischemia $(P=.542$; Figure E1).

\section{DISCUSSION}

Visceral ischemia is a life-threatening complication of $A B A D$ requiring urgent intervention. Mortality rates were similar after endovascular and surgical management, but they significantly increased when patients received medical treatment only. Early diagnosis of ABAD associated with visceral ischemia seems essential, and yet, presentation of visceral ischemia can be challenging, which may lead to crucial delays in diagnosis and treatment. ${ }^{8,9}$

Our analysis showed that, among ABAD patients, those suffering from visceral ischemia, compared with those without visceral ischemia, presented more often with abdominal pain and leg pain, and less often with chest pain. In cases of suspicion of ABAD with visceral ischemia, urgent additional imaging, preferably CTA, should follow. ${ }^{15,16}$ The mechanism of compromised visceral branch vessels can be both static and dynamic. Our analysis showed that in approximately $80 \%$ of cases, abdominal vessel involvement was seen on CTA imaging, suggesting that static obstruction had an important role in the visceral ischemia.

After CTA, however, doubts may remain regarding intestinal malperfusion caused by $\mathrm{ABAD}$, as no involvement of visceral arteries was seen in the remaining $20 \%$ of patients. These patients may have had dynamic obstruction by prolapse of the dissection flap into the vessel ostium, or CTA imaging quality may have been inadequate in these cases. Therefore, diagnosis of visceral ischemia should be made based on a combination of clinical signs, laboratory evaluation, CTA, and in some instances, endoscopic examination or dynamic imaging such as intravascular ultrasound. ${ }^{15,16}$

Surgical consultation immediately after confirmation of visceral malperfusion is indicated, as this strategy has been shown to reduce mortality. ${ }^{9}$ However, patients with $\mathrm{ABAD}$ and visceral ischemia remain a heterogeneous group of patients, with some suffering from only mild transient malperfusion, and others developing massive bowel necrosis. In addition, patients with visceral ischemia often suffered from associated limb ischemia and acute renal failure at admission, resulting in multi-organ failure. Clearly, definitive management depends on the duration and extent of ischemia. Urgent restoration of intestinal perfusion should be the first step in the management of visceral ischemia, followed by intestinal inspection and close observation of the patient. Intestinal resection may not always be necessary, as visceral malperfusion can be reversible when the ischemic period is minimized by early diagnosis and reperfusion. ${ }^{5,6,8,9}$

Unfortunately, data regarding bowel resection are not available in the IRAD. Restoration of intestinal perfusion can be achieved by various methods, including aortic endograft placement, endovascular fenestration, or visceral arterial stenting and surgical approaches such as fenestration or replacement of affected aortic segments. We observed a significant increase in the utilization of endovascular methods for the management of visceral ischemia over the years. The endovascular approach may be popular because it is minimally invasive, which is especially appealing when treating patients suffering from visceral ischemia who are in critical condition. Overall in-hospital mortality with surgical versus endovascular management was similar; however, the IRAD is an observational registry, so patient groups were probably not identical. Generally, the utilization of endovascular techniques for the management of complicated ABAD has dramatically increased and seems to lead to reduced mortality. ${ }^{17-22}$

Although, to our knowledge, no other studies have compared outcomes of endovascular versus surgical methods for $\mathrm{ABAD}$ with visceral ischemia, a few reports have evaluated these techniques for acute mesenteric ischemia in general. Beaulieu and colleagues ${ }^{6}$ studied acute mesenteric ischemia of various origins using the National Inpatient Sample Database. They found that endovascular repair of acute mesenteric ischemia increased during the study period, similar to our findings, and this change in care was associated with a $25 \%$ mortality rate, compared with $39 \%$ for patients treated surgically. Furthermore, endovascular repair was associated with fewer bowel 
resections, less need for total parenteral nutrition, and a shorter length of stay at the hospital. ${ }^{6}$ A study by Arthurs and colleagues ${ }^{23}$ found a $36 \%$ mortality rate after endovascular management of thrombotic and embolic mesenteric ischemia, compared with a 50\% rate after surgery. In addition, the mean length of resected bowel was shorter for patients treated endovascularly. Their report, like ours, was observational, so those undergoing surgery may have had more severe visceral ischemia and necrosis at diagnosis. It is generally accepted that a less-invasive endovascular approach seems appropriate as the primary modality, ${ }^{6,23-25}$ although in some cases, open or hybrid surgery cannot be avoided, as in cases of unsuitable anatomy for endovascular therapy or when laparotomy is needed for bowel resection.

After successful restoration of visceral perfusion, patients should be monitored closely, and the bowel should be inspected when there is doubt regarding its viability. Generally, bowel resection may be needed in $14 \%$ to $53 \%$ of patients presenting with acute mesenteric ischemia. $^{5-7,10,11,13}$ Simple laparoscopy can often be used to determine the need for bowel resection, and more-invasive laparotomy may be avoided in this manner. ${ }^{26}$ In addition, some studies suggest use of laparoscopy for second-look surgery on the day after bowel resection for ischemia. ${ }^{27,28}$

Nevertheless, even in cases of early diagnosis and treatment of ABAD with visceral ischemia, mortality rates remain high. Our analysis showed that medical management as the sole treatment was associated with increased mortality; acute renal failure and a descending aortic diameter $>5.5 \mathrm{~cm}$ tended to result in higher mortality as well. In the case of type A dissection with visceral ischemia, mortality rates may even exceed $60 \%{ }^{29}$ In the literature, advanced age, prolonged symptoms, impaired functional status, peritonitis, bowel necrosis, bowel resection, and postoperative sepsis all significantly affect mortality of acute mesenteric ischemia. ${ }^{8,10,11,13}$ Physicians should carefully take into account such factors and pre-existing medical conditions when determining appropriate treatment for the individual patient. Supportive management of very elderly and debilitated ABAD patients needs to be evaluated on a case-by-case basis.

To our knowledge, this study is the largest ever published on a cohort of patients suffering from ABAD with visceral ischemia; however, the findings should be viewed within the context of its limitations. Patients were not randomized to a predetermined management strategy, and therefore a selection bias could have been present. Furthermore, our definition of visceral ischemia does not distinguish among patients with varying degrees of intestinal ischemic injury. In addition, the IRAD does not contain data regarding bowel resection, an important element in the treatment of visceral necrosis.

\section{CONCLUSIONS}

Acute type B aortic dissection complicated by visceral ischemia carries a high risk of mortality. We observed similar outcomes for patients treated by either endovascular management or surgery, whereas medical management was an independent predictor of mortality. Early diagnosis and intervention for visceral ischemia seem to be crucial.

\section{References}

1. Golledge J, Eagle KA. Acute aortic dissection. Lancet. 2008;372:55-66.

2. Wheat MW Jr. Acute dissecting aneurysms of the aorta: diagnosis and treatment1979. Am Heart J. 1980;99:373-87.

3. Elefteriades JA, Lovoulos CJ, Coady MA, Tellides G, Kopf GS, Rizzo JA. Management of descending aortic dissection. Ann Thorac Surg. 1999;67:2002-5.

4. Hughes GC, Andersen ND, McCann RL. Management of acute type B aortic dissection. J Thorac Cardiovasc Surg. 2013;145:S202-7.

5. Char DJ, Cuadra SA, Hines GL, Purtill W. Surgical intervention for acute intestinal ischemia: experience in a community teaching hospital. Vasc Endovascular Surg. 2003;37:245-52.

6. Beaulieu RJ, Arnaoutakis KD, Abularrage CJ, Efron DT, Schneider E, Black JH III. Comparison of open and endovascular treatment of acute mesenteric ischemia. J Vasc Surg. 2014;59:159-64.

7. Endean ED, Barnes SL, Kwolek CJ, Minion DJ, Schwarcz TH, Mentzer RM Jr Surgical management of thrombotic acute intestinal ischemia. Ann Surg. 2001; 233:801-8.

8. Newton WB III, Sagransky MJ, Andrews JS, Hansen KJ, Corriere MA, Goodney PP, et al. Outcomes of revascularized acute mesenteric ischemia in the American College of Surgeons National Surgical Quality Improvement Program database. Am Surg. 2011;77:832-8.

9. Eltarawy IG, Etman YM, Zenati M, Simmons RL, Rosengart MR. Acute mesenteric ischemia: the importance of early surgical consultation. Am Surg. 2009;75:212-9.

10. Park WM, Gloviczki P, Cherry KJ Jr, Hallett JW Jr, Bower TC, Panneton JM, et al. Contemporary management of acute mesenteric ischemia: factors associated with survival. J Vasc Surg. 2002;35:445-52.

11. Kougias P, Lau D, El Sayed HF, Zhou W, Huynh TT, Lin PH. Determinants of mortality and treatment outcome following surgical interventions for acute mesenteric ischemia. J Vasc Surg. 2007;46:467-74.

12. Dahlke MH, Asshoff L, Popp FC, Feuerbach S, Lang SA, Renner P, et al. Mesenteric ischemia—outcome after surgical therapy in 83 patients. Dig Surg. 2008;25:213-9.

13. Edwards MS, Cherr GS, Craven TE, Olsen AW, Plonk GW, Geary RL, et al Acute occlusive mesenteric ischemia: surgical management and outcomes. Ann Vasc Surg. 2003;17:72-9.

14. Hagan PG, Nienaber CA, Isselbacher EM, Bruckman D, Karavite DJ, Russman PL, et al. The International Registry of Acute Aortic Dissection (IRAD): new insights into an old disease. JAMA. 2000;283:897-903.

15. Wyers MC. Acute mesenteric ischemia: diagnostic approach and surgical treatment. Semin Vasc Surg. 2010;23:9-20.

16. Renner P, Kienle K, Dahlke MH, Heiss P, Pfister K, Stroszczynski C, et al. Intestina ischemia: current treatment concepts. Langenbecks Arch Surg. 2011;396:3-11.

17. Fattori R, Tsai TT, Myrmel T, Evangelista A, Cooper JV, Trimarchi S, et al. Complicated acute type B dissection: Is surgery still the best option?: A report from the International Registry of Acute Aortic Dissection. J Am Coll Cardiol Cardiovasc Interv. 2008;1:395-402.

18. Jonker FH, Trimarchi S, Muhs BE, Rampoldi V, Montgomery DG, Froehlich JB, et al. The role of age in complicated acute type B aortic dissection. Ann Thorac Surg. 2013;96:2129-34.

19. Khoynezhad A, Donayre CE, Omari BO, Kopchok GE, Walot I, White RA Midterm results of endovascular treatment of complicated acute type B aortic dissection. J Thorac Cardiovasc Surg. 2009;138:625-31.

20. Patel HJ, Williams DM, Meerkov M, Dasika NL, Upchurch GR Jr, Deeb GM Long-term results of percutaneous management of malperfusion in acute type B aortic dissection: implications for thoracic aortic endovascular repair. J Thorac Cardiovasc Surg. 2009;138:300-8.

21. Kische S, Ehrlich MP, Nienaber CA, Rousseau H, Heijmen R, Piquet P, et al. Endovascular treatment of acute and chronic aortic dissection: midterm results from the Talent Thoracic Retrospective Registry. J Thorac Cardiovasc Surg. 2009;138: 115-24.

22. Zeeshan A, Woo EY, Bavaria JE, Fairman RM, Desai ND, Pochettino A, et al Thoracic endovascular aortic repair for acute complicated type B aortic 
dissection: superiority relative to conventional open surgical and medical therapy. J Thorac Cardiovasc Surg. 2010;140:S109-15.

23. Arthurs ZM, Titus J, Bannazadeh M, Eagleton MJ, Srivastava S, Sarac TP, et al. A comparison of endovascular revascularization with traditional therapy for the treatment of acute mesenteric ischemia. J Vasc Surg. 2011;53:698-704.

24. Gagnière J, Favrolt G, Alfidja A, Kastler A, Chabrot P, Cassagnes L, et al. Acute thrombotic mesenteric ischemia: primary endovascular treatment in eight patients. Cardiovasc Intervent Radiol. 2011:34:942-8.

25. Acosta S, Björck M. Modern treatment of acute mesenteric ischaemia. Br J Surg. 2014;101:e100-8.

26. Ferlan G, Lospalluti M, Capone G, De Pasquale C. Mesenteric ischemia in a patient with an acute aortic dissection type A. One-step repair of the aortic and visceral lesions. Role of laparoscopy for timely diagnosis and treatment. Interact Cardiovasc Thorac Surg. 2011;12:835-6.

27. Anadol AZ, Ersoy E, Taneri F, Tekin EH. Laparoscopic "second-look" in the management of mesenteric ischemia. Surg Laparosc Endosc Percutan Tech. 2004;14:191-3.

28. Meng $\mathrm{X}$, Liu L, Jiang $\mathrm{H}$. Indications and procedures for second-look surgery in acute mesenteric ischemia. Surg Today. 2010;40:700-5.

29. Di Eusanio M, Trimarchi S, Patel HJ, Hutchison S, Suzuki T, Peterson MD, et al. Clinical presentation, management, and short-term outcome of patients with type A acute dissection complicated by mesenteric malperfusion: observations from the International Registry of Acute Aortic Dissection. J Thorac Cardiovasc Surg. 2013;145:385-90.

Readers who found these articles interesting may also like to read the following papers found in recent and future issues of our sister publications, Seminars in Thoracic and Cardiovascular Surgery and Operative Techniques in Thoracic and Cardiovascular Surgery!

State of the Art: Thoralf Sundt. Current Understandings and Approach to the Management of Aortic Intramural Hematomas. Semin Thorac Cardiovasc Surg. Summer 2014;26(2):123-131.

News and Views: John Elefteriades. Treatment of Aortic Aneurysm Disease: Role of Earlier Intervention. Semin Thorac Cardiovasc Surg. Expected publication August 2015. 


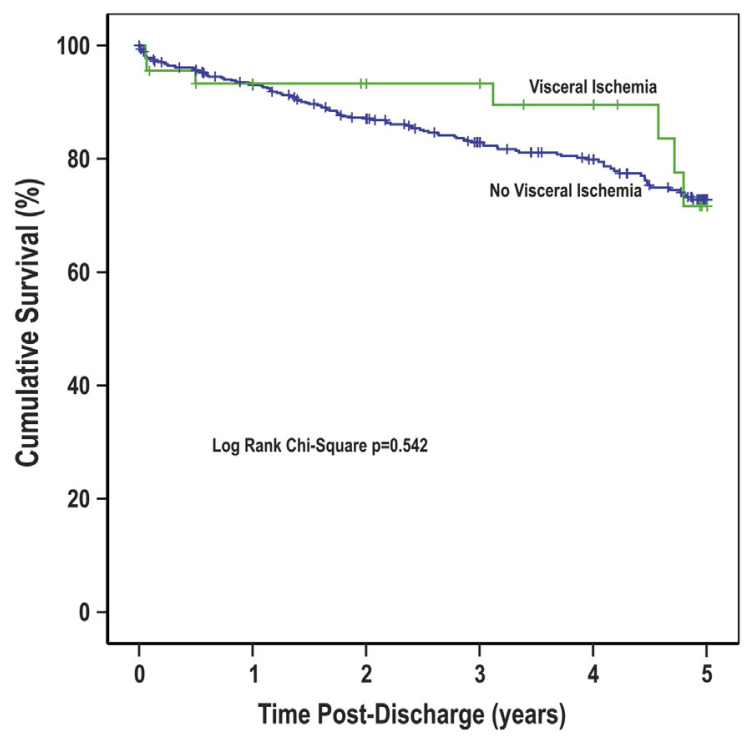

FIGURE E1. Survival of patients with and without visceral ischemia that were discharged alive. For these patients, no significant differences were found in survival during 5 years of follow-up between patients that presented with versus without visceral ischemia $(P=.542)$.

TABLE E1. Independent predictors of mortality among patients with visceral ischemia

\begin{tabular}{lclc}
\hline \multicolumn{1}{c}{ Variable } & Odds ratio & $\mathbf{9 5 \%}$ CI & $\boldsymbol{P}$ value \\
\hline Age $>70 \mathrm{y}$ & 0.94 & $0.17-5.2$ & .943 \\
Descending aortic diameter $>5.5 \mathrm{~cm}$ & 5.91 & $0.77-45.4$ & .087 \\
Hypotension/shock & 3.61 & $0.55-23.6$ & .181 \\
Acute renal failure & 3.74 & $0.93-15.1$ & .064 \\
Medical management & 5.91 & $1.2-31.0$ & .036 \\
\hline
\end{tabular}

CI, Confidence interval. 